\title{
After English: What do we Teach when we Teach Literary and Cultural Studies?
}

\author{
S V Srinivas*
}

\section{Abstract}

English Literature today is very different from what it was in the early 1990s, when the discipline was called upon to justify its existence by a vocal section of teachers and students. As a result of the changes inaugurated by the 'crisis in English Studies' and due to the comfort afforded by the demand for English language, the discipline has been relatively free from internal and external pressures to justify its existence. This is, therefore, a good time to raise the question of disciplinary relevance. I draw on my experience as a student, teacher and researcher formed by the 1990s to argue that the transformation of the discipline was at least partly facilitated by its investment in the engagement with texts and texutality. Reading and interpretation, albeit framed by a very different set of concerns, remain at the heart of Literary Studies as well as its offshoot, Cultural Studies. I, therefore, suggest that we consciously focus on building this capability, even as we introduce our students to an every-expanding range of textual forms.

Keywords: Capabilities and English Studies, Pedagogy, Close Reading in Literature

\section{Introduction}

The 1990s in India is often credited with the injection of high theory, and low culture, into the syllabi of English Departments. It was a time when the inventory of texts and authors was updated, broadening the scope of English Studies in ways that were

*Azim Premji University, Bengaluru, India; srinivas.sv@apu.edu.in 
unimaginable even a decade earlier. For me, the most important development of the 1990s is the urgency and immediacy with which students and teachers asked: what is the relevance of our discipline?

The question of relevance of English Literature is rarely asked by teachers in our country today with a similar degree of urgency. As a matter of fact, we may not even see ourselves as teachers of literature, because we have moved on to Cultural Studies. We cannot afford to be complacent just because in the Indian context English has always been linked to job opportunities and socioeconomic mobility. While English Departments are not under attack on account of their failure on the employment front, we have to take cognisance of how precariously literature, however broadly defined, is placed in the rapidly changing field of English Studies. Language teaching is already a distinct specialisation and it is possible that both Literary and Cultural Studies will be marginal to an English Studies that is primarily focussed on language teaching.

What then is our business, if it is not English language teaching alone, and if there are other people who claim they are better at that job anyway? In the much-discredited 'general education' model adopted by $20^{\text {th }}$ century Indian universities as well as the emerging 'liberal studies' one, the mandate of all Humanities disciplines is not to produce specialists - say engineers who can build or maintain machines - but to prepare students to do a range of things, from pursuing specialised courses of study to diverse careers for which specialised training is either not required or provided after selection (clerical and administrative jobs in the government, for example). Put differently, our students should be prepared-not on account of their parents' cultural (and other forms of) capital but on the strength of their training in the classroom - to move into emerging areas of study and employment alike. With specific reference to English, which I use as a convenient shorthand for the study of literature and other cultural forms, it is useful to revisit the 1990s for insights into capabilities that our students can expect to acquire and, more importantly, take with them to other, non-literary and non-academic domains. The conclusions I arrive at are redundant in that they are widely known. The reason to make my case at such length is that our 
pedagogic practice (what and how we teach) and research (what we do with exciting new texts and genres) does not always reflect these known knowns.

At first glance, a focus on the 1990s would appear counterintuitive. This was a period when an entire generation of teachers and students abandoned English Literature to do other things. Moreover, I was among those who moved away from the discipline. In this essay, I draw on my own experience of moving away from English Literature and into Film and Cultural Studies to suggest that discussions in English Departments played a critical role in shaping my academic trajectory. The larger point of my (self-indulgent) autoethnographic account is to return relevance as an important agenda item in discussions on the future of the Humanities in India. I am more than a little disturbed by writings that defend the Humanities by echoing Mathew Arnold's conceptions of culture. Foregrounding capabilities not only makes for a stronger defence of English Studies but also one that is more in tune with post-1990s developments in our discipline. Our task is to prepare the next generation of students to get out of the discipline and do things which we cannot, or dare not do.

\section{The Crisis}

Both as a student and teacher in the 1990s, I don't recall seeing a syllabus that had more than a paragraph of description, followed by a list of prescribed texts. It never occurred to me that I was meant to acquire (and later impart) a set of skills or capabilities. Whether or not our syllabus documents said it in so many words, literature teaching focussed on the appreciation of great works of authors. In other words, we acquired or cultivated a sensibility and gained incremental knowledge about a domain. The domain was a matter of broad consensus: there were certain authors, works, periods, genres, and so on, that were an essential part of a student's induction into the discipline. The method adopted for honing our sensibility and acquiring knowledge too was well established. The teacher provided some background information on an age or an author and expected students to learn how to read the written word with care, internalising what Tejaswini Niranjana termed, "New 
Critical obsessions with the words on the page" (1990, p. 2380). The standard test of competency was the interpretation of an unknown/unfamiliar poem or passage. The ability of students to gain admission into MA programmes could depend on this in some universities.

Towards the end of the last century, there were disruptions in this mostly-stable universe. There were entire courses based on primary and secondary texts gifted by Canadian and Australian governments. There was a joke that syllabi changed so drastically that publishers couldn't identify authors who could write guidebooks for them. More serious than broadening the literary canon was the challenge of delimiting the object of study and identifying methods of interpretation. Where does literature end, if at all? How do we study newer objects?

Studying literature was no longer about appreciating words on pages that were centuries old but about making texts - which may or may not be written - speak to our contexts. Even as more nonAnglo American writings began to be studied in literature classrooms, Niranjana noted that students in the early 1990s seemed "unwilling to be disempowered by metropolitan texts". Third World literatures appealed to the cultural nationalism of middle class students and, at the same time enabled, "English department students to question not only their own position of privilege but also the exalted status of their discipline in our postcolonial setting" (1990, 2382). A few years later, M. Madhava Prasad called for a much more expansive mandate for English Department in his critique of the discipline. He gave a call to the discipline to, " $[\mathrm{t}] \mathrm{o}$ wrestle with the complexities of contemporary life and test our critical intelligence in a field that defies familiar norms of cultural practice..." (2005, p. 67). ${ }^{\mathrm{i}}$

Notably, throughout the so-called crisis in English Studies in the late $2^{\text {th }}$ century, there was no external challenge to the exalted status of the discipline as the fount of culture. It was not as if bureaucrats and ministers were calling for the abolition of English departments or starving them of funds. The most devastating attacks came from within the discipline, launched by students and teachers. In Prasad's criticism of English Studies, for example, the use of the first person plural does not merely refer to the postcolonial nation 
but also students of the discipline, which he says had historically "taught $u s$ obedience, reverence for those who were better than $u s$, and other feudal virtues" (2005, p. 57, emphases added).

Taking stock of the developments during the decade, Rekha Pappu points out that the mandate of English Studies - to study "literary texts" - had in fact come to be questioned due to a variety of reasons. She argues that older "literary issues such as language, style, genres, canons etc. [lost] their disciplining function". For her, the core of the reconstituted discipline is "concerns such as egality, politics and democracy" (2005, p. 49). While critical theory facilitated "a move in democratic directions" a far more radical questioning began "in the early nineties when the institution of English [S]tudies was rocked by the assertive force of caste politics" (33). Gender had already begun to be accommodated without much resistance from the establishment but caste was truly disruptive because an overwhelming majority of the most elite English Departments were populated by upper caste teachers and students. The very presence of the odd non-upper caste student in the English classroom too was evidence of exclusion (Natarajan et. al., 1991).

If critical theory provided the conceptual tools, it was the postMandal context that brought the crisis quite literally to classrooms and university campuses. English Departments weren't the only ones to be impacted but they certainly were more willing to acknowledge the issues raised by Mandal agitation than others. The ongoing critique of the discipline's colonial legacies had only recently raised uncomfortable questions. In a context where access to English and caste-class privilege were directly linked, appreciating texts in that language was just about the most insensitive (or reactionary) thing one could do. With respect to social inequity, no other discipline outside the sciences was so directly implicated in everything that was wrong with the university system. Everything - content, methods and sensibility had to be changed. 


\section{Movement: Films and Other Texts}

Over the next decade, English Departments responded by reconceptualising what it meant to study literature. Arguably, the new sensibility of English was politics. Interest in the politics of representation in cultural texts and the more recent emergence of identity politics as a research focus are both traceable to late 1980s and 1990s discussions. English Departments were by no means the only sites for housing identity related concerns but since our universe revolves around texts and authors, there is no avoiding the thematic of representation at the level of the text and its producer alike.

From the 1990s, students and teachers of literature have been reading an ever-expanding range of texts and authors politically. Udaya Kumar points out there has been a fundamental change in how texts are read in the discipline. Whereas in earlier decades the study of literature involved appreciating texts in elaborate, wellwritten plot summary-type elucidations, the turn of the century student was engaged in showing up texts and writers for their bad politics (Kumar, 2019). Among the manifestations of the changing mandate, objects of analysis and practices of reading is the spate of papers as well as MPhil and $\mathrm{PhD}$ dissertations on representation of race, class, caste, gender, sexuality, childhood, and so on in an author's work, or entire genres.

Till the 1990s, English in India was relatively insulated from the Structuralism and the Post-Structuralist turn in the Humanities and Social Sciences. However, far more interesting approaches to texts than a focus on the 'words on the page' were sinking roots in other disciplines, ranging from History to Sociology. Ranajit Guha and other Subaltern Studies Collective historians had adopted textual analysis in their examination of archival material from the 1970s (see for example a fascinating semiotic analysis of colonial archival records in Guha, 1983a). In a parallel development, Anthropological and Sociological studies began analysing textsthat too popular texts - from the 1980s. Notable in this regard are Veena Das's essays on the Hindi film, Jai Santoshi Maa (Sharma, 1975) and the American novelist Ira Levin's writings (Das, 1981, 1988). Even in the Indian context, therefore, what were earlier 
considered literary methods were being deployed by scholars in other disciplines.

The 1990s was an interesting time for the study of non-literary forms, cinema in particular. I will stay with the cinema because of my investment in it, and also because of the excitement it generated. Then as now, academic interest in the cinema far exceeded the marginal presence of university departments specialising in Film Studies. The first department of Film Studies in India was established in Jadavpur University in 1993. It remains one of the few such departments in the country. Before the 1990s too there was a steady trickle of academic writings on the cinema but it was with the 'Roja debate' that popular cinema attracted widespread academic interest. Carried out in the pages of Economic and Political Weekly (EPW), the Roja debate, as it came to be called later, is a set of seven essays on the Tamil film Roja (Mani Ratnam, 1992), which was also released in the Telugu and Hindi dubbed versions. Prompted by Tejaswini Niranjana's article (1994), these essays were centred on the politics of popular cinema. The Roja debate was in fact preceded by essays on popular (south Indian) cinema in EPW by M.S.S. Pandian (1991) and Niranjana herself (1991). EPW discussions on popular cinema did not have a disciplinary focus and addressed non-academic readers too.

In $E P W$ and elsewhere, writings on the cinema were not in any obvious way linked to English Studies. At the same time, politics as the new sensibility of literature was a key facilitator of the turn to the popular.

As the canvas of English expanded, we found ourselves in the company of researchers who too worked with textual forms and/or were interested in the popular. The turn towards the popular was an opportunity to study the contemporary in all its complexity. It generated much excitement and also presented an interesting challenge for students of English. Unlike the Sociologist who went to the movies with her knowledge of caste, kinship, religiosity, and so on, the literature student had little domain knowledge to bring to the analysis of objects of representation. Neither could she claim a greater degree of familiarity with the textual forms under 
consideration than the next researcher, because English Departments remained focussed on the written word.

We therefore faced a variant of the relevance question. What good was/is an English Literature training in projects that are no longer concerned with the literary text? Although the movement away from the literary was not the sole, or even the most striking development of the period, the '90s sensibility was certainly a key factor insofar as it led us to the popular, as a more immediate and important site for political contestation, than the literary. When I panned out of the literary and into world of representations beyond, was I equipped with anything other than a sensibility, which partly developed in conversation with teachers and students in my discipline and partly in reaction to an older conception of the literary?

In the sections that follow, I examine my movement away from English Studies to ask if competencies associated with literature were transferable to contexts in which domain knowledge of my parent discipline was not useful.

\section{Exit}

In early 1996, I returned to my PhD at the English Department in the University of Hyderabad. I had registered in 1991 but left in 1992 to teach in what was then Arunachal University (now Rajiv Gandhi University) in Itanagar. In the intervening period, I was actively contemplating careers other than teaching English. This, in spite of my dream job in Arunachal Pradesh. Among other joys of being in Arunachal was the unimaginably small classes I taughtmy first MA class had just two students. Although student strength grew gradually, teaching was light and lecturing stopped entirely by February, when students stopped coming to class to prepare for the annual examination in April-May. There were no 'internal assignments' to grade either.

My courses ranged from Literary Criticism, 18 1 th Century (British) Literature and Indian Writing in English. Soon after I started teaching, we revised the MA syllabus, updating it to reflect debates in the discipline. Even the revised syllabus, however, not just what I taught, didn't seem to make much sense in that place and time. In 
Arunachal Pradesh, like in several other parts of India, English was considered too difficult for the average student (therefore the small class size). While there were exceptions, most students who enrolled in MA had done so because of the opportunities opened up by the language, not because of their interest for literature in English. The experience was (is?) a familiar one in English Departments in India, outside the central and/or metropolitan university bubble.

In Arunachal University, I was not just an outsider to the regionfrom the 'mainland' as some people used to put it in those daysbut the churning in my parent Department, and others elsewhere, offered no resources to engage with the new context. There were exciting research possibilities and a collaborative project too, carried out with three colleagues from other disciplines on the thriving video parlours in neighbourhood villages, which screened Hindi, Hollywood and Hong Kong (martial arts) films. The project gave me several insights which I carried to my $\mathrm{PhD}$ later on but it was completely unrelated to English and literature alike. In a manner of speaking, research possibilities offered by my new context too led me out of the discipline.

Within no time, I lost interest in my original $\mathrm{PhD}$ proposal which was on the institutionalisation of English teaching in Indian universities. That project was shaped by post-colonial critiques of the discipline by authors like Ngugi wa Thiong'o (1987). If completed, it would have complemented Gauri Viswanathan's Masks of Conquest (1990) in some respects. The project held a lot of promise in the well-established university department back in Hyderabad but in Arunachal it didn't seem to matter to anyone. Least of all to my students who were struggling to comprehend complex texts in a language they did not quite master in school and college.

In 1996, I was sure that my new project did not belong to English Studies. The new proposal, rather disingenuously, claimed that the project would juxtapose representations of popular cinema in Indian writing in English with its circulation among actual audiences. In fact, I knew very well that it was going to be focussed on Telugu cinema's stars and their fan clubs. The novels that 
figured prominently in the proposal would make a very brief appearance in the final thesis (Srinivas, 1997).

I was excited about studying a phenomenon that was unfolding before me. Moreover, Telugu cinema was an intimate form. I had grown up watching films, mostly Telugu ones. On the academic front, there were inspiring developments related to cinema. The links between films and politics in southern India had only recently been the subject of book length studies by Chidananda Das Gupta (1991) and Pandian (1992).

It is only in hindsight that the multiple ways in which English Studies had laid the ground for what I thought was my exit became apparent. For starters, the English Department in Hyderabad did not object to my project, in spite of its obvious digression from the literary as object of analysis, and English as language of texts. Around this time other researchers in the Department, including Rekha Pappu whom I cited above, too had begun to work on either non-literary and/or non-English materials. What all of us had in common was the desire to engage with the political in general and questions of caste, gender and class in particular. Although it was the socio-political churning of the 1990s that honed our interest in political questions, we were fortunate to be a part of a discipline that could no longer prevent us from bringing them to the classroom and research projects. I distinctly recall that the degree of investment and immediacy with which we approached our projects was strikingly absent in most other Humanities and Social Science departments in the university.

Returning to my questions, what did English Studies have to do with Telugu cinema?

\section{Under-reading Texts}

I was interested in a phenomenon - a distinctive form of fandom that was publicly staged and had obvious links with caste and political mobilisations. Anthropology, not English, was the natural home for my project. Fans performed a range of activities in different spaces and also painstakingly archived these. Moreover, fans consumed and produced a range of ephemeral objects - from magazines to stationery. Although I had no training in 
ethnographic methods, I was determined that 'fieldwork' would be one of my methods. I was not worried about my lack of training.

I found two studies on Tamil cinema particularly enabling, and for different reasons. The Anthropologist Sara Dickey (1993) had worked on fans clubs of the Tamil star M.G. Ramachandran, drawing attention to the range of activities they carried out in her book, Cinema and the Urban Poor in South India. The overlaps between her work and my project gave me the confidence that my pursuit would be worthwhile. Pandian (1992) too had discussed fan ephemera in The Image Trap. Pandian was not an Anthropologist. Moreover, he too had moved out of his parent discipline (Economics), to engage with his immediate political context which continued to be shaped by stars turned politicians.

At the same, I was dissatisfied with Dickey and Pandian's approach to texts and textuality. I thought their discussion of texts was perfunctory and that they had not done enough with their material. In this respect Pandian's book was surprising, and disappointingly so because it was in stark contrast with his essay on the 'DMK film' published shortly before his book (Pandian, 1991).

Pandian's essay is a close reading of the classic Tamil film Parasakthi (Krishnan-Panju, 1952) that is grounded in the film's historical and political contexts. He offers a detailed account of the film's thematic concerns and formal features alike. In fact, his description of the genre elements of DMK propaganda film in The Image Trap is directly traceable to this essay: "These films... propagated atheism, Tamil nationalism (which was often couched in anti-North and anti-Hindi rhetoric) and anti-Brahminism. The narratives of these films were peopled by womanising temple priests/religious men, helpless deities, usurious north Indian money-lenders and villainous Brahmins" (1992, p. 34). In addition, the essay offers a textbook example of 'reader-response criticism' by providing us a rich and detailed account of the responses of the opponents of the film. Pandian reads statements made by the films' opponents - who range from representatives of the Congress Party to government officials - to help us understand what was seen as objectionable in the film. He also reads his sources against the grain 
of their statements to identify elements that appealed to the rest of the film's audience, which received it with great enthusiasm. These sections of the audience did not leave behind written testimonies on the film but their behaviour was recorded by educated, upper caste viewers who were scandalised by the film. Coincidentally, Miriam Hansen's landmark work on American silent cinema was published in the same year as Pandian's essay (Hansen, 1991). Hansen, among other things, presents her readers with a fascinating account of female spectatorship based almost entirely on news and other reports authored by men. Closer home, Pandian's method is traceable to Ranajit Guha's reconstruction of peasant rebellions from the accounts left behind by colonial administrators and their supporters (Guha, 1983b).

As an instance of textual analysis, Pandian's essay on Parasakthi is exemplary and even more strikingly so because he does not explicitly draw on terms and concepts used in literary criticism and theory.

In The Image Trap, Pandian adopts a different approach. One of the strengths of the book is the fascinating range of fan materials, from hagiographic 'popular biographies' of the Tamil star-turnedpolitician MG Ramachandran to poems and songs in his praise, that it discusses. The book juxtaposes MGR's film and political careers by analysing some key films, the star's public utterances and gestures as well as the policies of his government. The book's resources are far more expansive than the elite and state-centric documents Pandian's Parasakthi essay discusses. At the same time, in spite of frequent references and quotations from films and other popular texts, the book does not read texts closely. Evidence for what Pandian calls "the political devotion of the subaltern classes to $\operatorname{MGR}^{\prime \prime}(1992$, p. 21$)$ is presumably available in the plethora of texts he flags. But these texts themselves are presented as transparent carriers of meanings that are waiting to be discovered. For example, he quotes the lyrics of 'ideological songs' from two MGR starrers at some length to observe that "these songs are treated by the common people as the ideological statements pronounced by MG Ramachandran, the actor-cum-politician, himself" (1992, 54-55). The deliberate conflation of film and political careers of MG Ramachandran was noted earlier by Robert 
Hardgrave Jr. (1973 and 1979). Film theorist Richard Dyer (1991), writing about a very different context argues that stars always have a double existence: as characters in a fictional work and as 'real' people. Both versions of the star, Dyer goes on to argue, are textually fabricated. Pandian tells us this was so in MG Ramachandran's career. But he does not quite show how films work, in and as webs of signification.

Dickey's book (1993) begins with a description of the contexts of Tamil cinema in general and Madurai in particular. She then discusses the reasons for Tamil cinema's appeal for audiences. The third and final section of the book - the operative sections as far as I was concerned-explore the relationship between films and audiences. For Dickey, the cinema is not a trap. Even if it is largely about escape from reality, she states at the very beginning of the book, film viewing involves a process of negotiation, and, by implication, meaning- making on the part of the audience. In her analysis of films, she alerts the reader to the formulaic nature of popular Tamil/Indian cinema-the song and dance routines, comedy track and fight sequences-and how filmmakers work with elements that are familiar to their audiences. She then discusses in some detail three representative Tamil films that were released in the late 1980s (1993, pp. 72-88). These are elaborate plot summaries, and, by the author's own admission, not meant to be close, textual analyses. In disciplinary terms, as she herself notes, this level of engagement with the filmic text is sufficient (1993, p. 71). The disclaimer notwithstanding, I was struck, and disappointed, by what I thought was the relative lack of attention to films, which were after all at the heart of matter.

\section{Thin and Unwieldy Texts}

My approach to films, stars, their fans and other audiences turned out to be far more text-centric than I had initially envisaged. Fans of Telugu film stars, like fans in many other parts of the world, were immersed in multiple genres of texts. Some of these-most notably films - were consumed by them while others were produced by them. My move away from literature to the study of activity/behaviour was therefore not such a major one, in a manner 
of speaking, because I continued working with texts. Although 'fieldwork' which involved observation of fan activity/behaviour remained an important component of the project, film history and detailed analysis of individual films became increasingly important for my study. Not only because of my levels of comfort but also because fan activity is, among others things, a response to films. An understanding of how films work as fan-texts, I felt, was necessary for researching fans. Detailed analyses of filmic texts had not received much attention in the work of Pandian and Dickey.

Neither was analysis of filmic and televisual texts a major focus of the emerging scholarship on what soon came to be called fan (or fandom) studies in the Anglo-American academy. Studies of audiences had by the 1990s begun to focus on texts generated by fandom and studied them. I had had a glimpse of this field from Lisa Lewis' collection of essays on audiences (1992). There was also Vermorel and Vermorel's (1985) work on 'groupies' of UK-based musicians which alerted me to fan mail as a valuable resource. Regrettably, I read Henry Jenkins' classic on Star Trek fans, Textual Poachers (1992) only after I completed my PhD.

The textualisation of fan activity in my work had to do with writings on audiences that I came across as well as and my discovery of a range of ephemeral objects that neither Pandian nor Dickey discussed. In addition, my focus on texts helped me address an interesting problem thrown up by fieldwork: the gap between what collaborators say -in all earnestness - they are doing and what their activities appear to signify. Within weeks of fieldwork I realised that fans were repeatedly saying things that they thought I wanted to, or ought to, hear: caste didn't matter, they loved watching 'class films' (which made artistic claims) and not formulaic 'mass films', they were deeply loyal to their idols and would do anything that was asked of them, and so on. Years later I came across discussions in Anthropology about the problem of collaborators saying things that they know to be untrue, and sometimes know that the researcher too knows to be untrue. Back then, I was assembling methods of triangulation from scratch, to deal with what in my limited understanding was a variant of intentional fallacy. 
Orally and in writing, fans made a number of proclamations about their intent (selfless devotion). Their actions, on the other hand, connoted a degree of autonomy from expectations that stars had of them, and even outright defiance of clearly stated regulations they were expected to adhere to. For example, Chiranjeevi fans were instructed not to participate in political campaigns. No selfrespecting fan club in Vijayawada, where I spent months with fans of different stars, followed this instruction. I was well aware of inconsistencies and internal contradictions in statements made by fans. Sometimes, I confronted my closest collaborators, those with whom I had built a rapport, with these inconsistencies. They would admit that they tried to misinform me (there were denials too). Dickey and, in a later work, Purnima Mankekar (1999) cite viewers saying they watch films and television respectively to gain knowledge. I heard similar statements repeatedly but knowing the rowdy-ness of fan behaviour in cinema halls, I never believed them for a second. But I could not rely on the occasional 'confession' by a fan whom I had befriended. I therefore sought explanations for fan activity in fans' public performances and texts, which I could read closely and in conjunction with other texts as well as performances.

In the process of making my research text-centred, I hit a major obstacle for which my literature training did not prepare me. Like most others working on popular culture, I was dealing with a large volume of material. In the literature class, we read closely a limited number of texts that are linguistically and conceptually dense and complex. In contrast, popular texts tend to be thin and don't easily lend themselves to close reading. There is only so much one can say about their lack of sophistication and sameness. Material as diverse as fan mail and films of the star posed interesting challenges on account of their sheer numbers and thinness. What does a literature student do with sameness and/or lack of substance? Let me explain my problem and the ad-hoc solutions I found for it with reference to fan mail and formulaic star vehicles that south Indian stars acted in by the dozen to engender and sustain their substantial fan following.

Fan mail received by Telugu film stars in the 1990s is a good example of a thin text. In 1996, when I got permission to access (snail) mail received by the Telugu 'Megastar' Chiranjeevi (his 
office typically received two to three dozen letters from fans per day). Over the previous year, the office had collected thousands of letters, storing them in large cardboard boxes. Almost all mail was periodically thrown away so I was free to take away as many letters as I liked for closer examination. Thanks to Sivaji, the official ghost writer whose job it was to read all letters and reply to the routine ones in the star's name, I learnt that there were essentially two categories of fan mail. The first was a short-usually three to four sentence long-and straightforward request for photographs of the star and/or information about future releases. The second category consisted of a small fraction of the total mail received and its distinguishing feature was that it had some content. This could be fan organisations' reports on the good work they had undertaken in the name of the star, strident criticism of the star's recent work or the occasional suicide threat by fans who had either not received responses to their earlier letters or failed to meet their idol.

All fan mail was repetitive, even generic. This was true even of photographs sent by fans to the star. Most pictures came from organised fans who had their own letterheads, rubberstamps, organising committees and other forms and keepings of a proper bureaucracy. Fans would have themselves photographed while performing an activity in the name of the star. Images tended to be of mediocre quality and frontal-often featuring dozens of fans staring at the camera, with cloth banners marking the occasion and organisation in the background.

Fan mail and other productions that had been studied in the AngloAmerican context were expressive, even sexual (Vermorel \& Vermorel, 1986). It evidenced resistant readings, instances of 'textual poaching', and so on (Jenkins, 1992). Evidently, these researchers had either suppressed information about boxes of numbingly repetitive writings, or had found more articulate fans than I did. Be that as it may, there was no escaping the fact that my texts did not lend themselves to close reading. Genre categorisation was far too easy and pointless. It only added to the challenge of meaning making.

I ended up adopting what I could have called 'surface reading' (Best \& Marcus, 2009) at a later stage in my career. However, my 
surface reading was not to "describe texts accurately" as the advocates of this approach intend to do. I was trying to make sense of an entire archive by placing its elements in relation to each other and to other kinds of texts to which they were intimately linked. My inferences from fan mail were, expectedly, different from researchers studying fandom in other contexts. Letters and photographs, I argued, should not be read for their non-existent substantive content but as utterances flagging the existence of an individual or a group of fans. Fan texts call attention to the existence of the fan-as-fan, his fanness.

Fans' practice of calling attention to themselves becomes interesting when seen in the context of their activities in cinema halls. Fans are widely known to be 'repeaters' who watch films multiple times. Now, film viewing is by design a one-way communication. Further, in the contexts that I examined, fan viewing is collective and boisterous, involving much dancing, whistling and shouting. In order to understand the place of films in the fan universe I focussed on those moments that elicited the most enthusiastic fan response in movie theatres. Arriving at the filmic text from fan activity presented me with an object of analysis that was differently constituted than the one, which had a story and characters, belonged to a genre, and so on. Focus of my study therefore shifted away from the unfolding of the plot to the construction of narratives around sequences that were predictable, formulaic and, at the same time, finely crafted. Opening sequences in general and the elaborately choreographed introductions of the star in the film were among the segments that I analysed in detail.

\section{Thin Texts and Politics}

To stop here would mean sidestepping the question of the political. For starters, fans calling attention to their excessive enjoyment of films of their stars is the most obvious thing about fandom of this particular variety. The films I examined are deeply 'ideological' in that they offer impossible solutions to real world problems. Or worse, raise socio-economic and political problems only to move on to a gripping revenge drama. And in any case, as Prasad points out, ordinary people shown in films are almost always incapable of 
political action, unless this is limited to nominating the starprotagonist to solve their problems (Prasad 1998, 138-159). Several authors, including Das Gupta, Pandian and Dickey had noted this earlier. In any case, fan enthusiasm-the discourse of undying loyalty, extreme acts of devotion-presents itself as evidence of successful manipulation by the cinema and its stars (and therefore the ruling caste-class elite).

Reading fandom as evidence of manipulation however, does not quite account for the forms and keepings of fan activity. For instance, during a film's opening week, fans do everything in movie theatres other than focussing on the screen. ${ }^{\text {ii }}$ Of course, they come back later to watch the film more carefully but how do we make sense of the inverse relationship between attentive viewing and their enjoyment of films? Further, fans are just as vocal and 'active' about expressing their displeasure and disapproval as their enthusiasm for their idol's work.iii We therefore need to explain forms of (distracted) devotion as well as acts of defiance by the presumed-to-be-faithful.

Neither submission to the authority of the star nor 'resistance' capture what might be political about films, stars and fans. Let me note in passing that resistance was the hallmark of 'Cultural Studies' approaches to popular culture during the turn of the 20 2 th century and I too initially subscribed to it. As I mentioned in passing earlier, even before Chiranjeevi joined politics, there were easily discernible linkages between fan organisations and caste and/or political mobilisation in parts of Andhra Pradesh. At the same time, fans were not engaged in oppositional politics of any recognisable kind.

Based on my observations of fan activity/behaviour in cinema halls and the material they produced, I argued that fans have a highly evolved sense of entitlement. Their entitlements are not immediately or obviously political: they are not about economic benefits, political representation and other big issues. But, as Ashish Rajadhyaksha argued around this time, the entitled viewer mirrors the political subject who in a democracy is already/always granted a set of well-defined rights (Rajadhyaksha, 2000). It is the recognition of viewers' entitlement - to be present before the screen 
in the first instance - that makes the cinema an important publicpolitical institution.

Film as fan-text is a particularly useful heuristic object because its narrative is woven around a series of formulaic set pieces. A formula is usefully seen as a crystallisation of viewers' expectations. The fact that formulaic films are prone to failure at the box office, and in fan circles, tells us something about how difficult it is to anticipate the exact combination of elements that will match up to viewer expectation. I couldn't help noticing that in the mid-1990s, when I was working on my PhD, a majority of films Chiranjeevi acted in were failures at the box office. Between manipulative intent and its acceptance lies fandom.

The big question then would be what cinema and fandom facilitates for those who are its subjects. This is not a rhetorical question because the answer certainly is not compliance to the master's will. While researchers are presumed to start with a question and then find the texts, contexts and reading strategies that facilitate its exploration, I arrived at an early version of my question after the actual research was over, while writing the thesis. I could formulate my question clearly around 2008 only when I revisited my material while writing Megastar (Srinivas, 2009). By this time, my break from English Literature was exactly a decade old-I had quit Arunachal University and teaching English in early 1998. And yet, Megastar is far more text-centric than my PhD thesis. Films and fan productions discussed in Megastar are significantly higher in number and the discussion of films longer. After Megastar too I constantly returned to close reading, even as I worked with diverse non-film materials.

Returning to the issue with which I began: what did English, as the convenient and embarrassing shorthand for English Studies that has at its core close reading, prepare (students like) me for? What relevance does it have now, when mastery over the literary canon is not at premium among admission seekers and teachers alike? Speaking entirely for myself, the movement away from English was enabled by my facility for reading texts. From ephemera to behaviour - which Anthropology had by then already designated as the object of interpretation-explorations of form, connotation 
and intertextuality were the nodes around which my research was organised.

What my training did not prepare me for was the possibility of, and need, to take the tools of literary analysis to other texts. Literature was presented as an end in itself. Looking back, this was possibly one of the reasons for the erosion of the discipline's credibility in the 1990s. Thankfully, this approach to the literary is now passé. Freedom from the past comes with an important challenge. We are not constrained by the Anglo-American canon any longer and have been offering courses on myriads of textual forms. Domain knowledge is no longer our sole focus. Chances are that our students are far more familiar with these forms than us. Even otherwise, we need to take a hard look at what, under these not-so-new and still-happy circumstances, we can offer our students. There are innumerable texts and an ever-increasing number of forms out there. Archives so large that corporations and scholars alike are turning to machines to make sense of them. In our text-mediated world, the ability to engage critically with them is a life skill. Our business has always been teaching students to read texts. And yet, we have devoted more time and energy to syllabus change than ways in which we can build the capability to read, interpret. In a great deal of Literary, Cultural and Film Studies writing, the dead giveaway of an author's 'English' background is the elaborate plot summary. Evidently, all the volumes written on reading texts - closely and in depth, on the surface and from a distance-haven't quite translated into a pedagogic and research practice that can help our students but also us, acquire a mastery over this capability.

Let me conclude by first of all pointing out periodic revisions of syllabi are necessary and welcome but shuffling texts and authors does not address the capability question. Increasing social and economic diversity of students in English classrooms makes the question all the more immediate. Speaking for myself, foremost on the minds of the faculty group in my university is how we can we prepare students with limited exposure to the English language and limited exposure to literature in any language to engage with texts. Reflections on teaching from the 1990s indicate that syllabi grounded in context that students can relate to are better received 
in the classroom than texts drawn from the older canon. However, neither the expansion of the literary canon nor the turn to cinema and other popular forms has been accompanied by a reflection on how capabilities can be built and transferred. In courses on Literature, Cultural Studies, Visual Culture and Cinema alike, syllabus documents made public by English Departments indicate that the discussion of methods is either entirely absent or is neatly separated from the analysis of texts. The underlying assumption, perhaps, is that students either learn about analytical tools and procedures across papers on literature, or 'on the go' in emerging areas of study. For reasons mentioned early in the paper, this is a good time for us to prioritise familiarising our students with procedures and tools of analysis in most, if not all, courses. As students, some of us have been in classes where teachers did precisely this. We too can attempt to do so, even with our existing syllabi, by calling attention to what we look for when we encounter texts, old and new.

\section{Acknowledgements}

An early version of this paper was presented at the National Symposium on "Rethinking English Studies in India: The Cultural Studies Turn and Its Possibilities" organised by the School of Business Studies and Social Sciences, Christ (Deemed to be University), Bengaluru on $14^{\text {th }}$ February. Many thanks to my colleague Neeraja Sundaram for her questions and comments.

\section{References}

Best, S., \& Marcus, S. (2009). Surface reading: An introduction. Representations, 108(1), 1-21.

Das, V. (1981). The mythological film and its framework of meaning: An analysis of "Jai Santoshi Ma". India International Centre Quarterly, 8(1), 43-56.

Das, V. (1988). Science and violence in popular fiction: four novels of Ira Levin. In A. Nandy (Ed.) Science, hegemony and violence: A requiem for modernity. New Delhi: Oxford University Press, (211-231).

Gupta, C. D. (1991). The painted face: Studies in India's popular cinema. Roli Books.

Dickey, S. (1993). Cinema and the urban poor in South India. Cambridge University Press. 
Dyer, R. (2003). A star is born and the construction of authenticity. Stardom, (155-163). Routledge.

Guha, R. (1983a). The prose of counter-insurgency. In R. Guha (Ed.) Subaltern studies II: writings on South Asian History and Society. New Delhi: Oxford University Press.

1983b. Elementary aspects of peasant insurgency in colonial India. Delhi: New Oxford University Press.

Hansen, M. (1991). Babel and Babylon: spectatorship in American silent film. Cambridge, MA.: Harvard University Press.

Hardgrave, R. L. (1973). Politics and the film in Tamil Nadu: The stars and the DMK. Asian Survey, 13(3), (288-305).

- - . (1979). When stars displace the gods: The folk culture of cinemain Tamil Nadu. In Essays in the Political Sociology of South India. New Delhi: Manohar.

Jenkins, H. (2012). Textual poachers: television fans and participatory culture. Routledge.

Kumar, Udaya. (2019). Reading and cultural studies turn. Paper presented at the National Symposium on Rethinking English Studies in India: The Cultural Studies Turn and Its Possibilities. School of Business Studies and Social Sciences, CHRIST (Deemed to be University), Bengaluru, $14^{\text {th }}$ February.

Lewis, L. A. (2002). The adoring audience: fan culture and popular media. Routledge.

Mankekar, P. (1999). Screening culture, viewing politics: An ethnography of television, womanhood, and nation in postcolonial India. Duke University Press.

Moretti, F. (2013). Distant reading. Verso Books.

Natarajan, S., Nigel J. \& Srinivas, S.V. (1991). The anatomy of a white elephant: notes on the functioning of English departments of India, Journal of English and Foreign Languages, 7 \& 8 (June and December).

Niranjana, T. (1990). 'History, really beginning': compulsions of postcolonial pedagogy. Economic and Political Weekly, 25(42/43), 2379-2384. (1991). Cinema, femininity and economy of consumption. Economic and Political Weekly, 26(43), WS85-WS86.

(1994). Integrating whose nation? Tourists and terrorists in Roja. Economic and Political Weekly. 29(3), 79-82.

Pandian, M. S. S. (1991). Parasakthi: Life and times of a DMK film. Economic and Political Weekly, 759-770.

- - - (1992). The image trap: M.G. Ramachandran in the film and politics. Delhi: Newbury Park, London: Sage. 
Pappu, R. (2005). English studies in India: critical moments. In S. Poduval (Ed.), Re-figuring culture: history, theory and the aesthetic in contemporary India. New Delhi: Sahitya Akademi, 17-55.

Prasad, M. M. (1998). Ideology of the Hindi film: A historical construction. New Delhi: Oxford University Press.

(2005). Teaching capitalism as a native language. In S. Poduval (Ed.), Re-figuring culture: history, theory and the aesthetic in contemporary India.

New Delhi: Sahitya Akademi, 56-67.

Rajadhyaksha, A. (2000). Viewership and democracy in the cinema. In R.

S. Vasudevan (Ed.), Making meaning in Indian cinema. New Delhi: Oxford University Press, 267-96.

Srinivas, S.V. (1997). Fans and stars: production, reception and circulation of the moving image. PhD Dissertation submitted to the Department of English, University of Hyderabad.

(2009). Megastars: Chiranjeevi and Telugu cinema after N.T. Rama Rao. New Delhi: Oxford University Press.

Vermorel, F., \& Vermorel J. (1985). Starlust: The secret fantasies of fans. London W.H. Allen.

Viswanathan, G. (1990). Masks of conquest: literary study and British rule in India. London: Faber and Faber.

WaThiong'o, N. (1992). Decolonising the mind: The politics of language in African literature. East African Publishers.

\section{Endnotes}

i Prasad's paper was originally presented at the seminar on "New Directions in English Studies" at the University of Hyderabad in 1995.

ii In the more recent past, fans have taken to making videos of themselves dancing and screaming during screenings and uploading them on YouTube. There are several YouTube videos of fans cheering the 'transformation scene' of the Tamil actor Ajith's Vedalam (Siva, 2015). This one was apparently shot on the $365^{\text {th }}$ day of the film's run in a theatre: https://www.youtube.com/watch?v=IGOoiYWtrD8.

iii I discussed examples of fan disapproval at some length in Srinivas 2009. 